\title{
La práctica trashumante pehuenche en la Araucanía andina: una forma de construir y habitar los territorios de montaña del sur de Chile
}

\author{
Carla Marchant ${ }^{1}$
}

\begin{abstract}
El objetivo de este trabajo es comprender y reflexionar sobre el significado de las principales prácticas que componen la trashumancia pehuenche realizadas por una comunidad en Lonquimay y cómo esta práctica, basada en el conocimiento ecológico local, construye y significa el habitar de un territorio de montaña de la Araucanía andina. Se postula que las prácticas desarrolladas por la comunidad durante el trayecto trashumante, poseen una significancia y valoración social, cultural, ambiental, identitaria y económica, que transforma a este territorio en un espacio donde la experiencia existencial del habitar es clave y pilar de su devenir.
\end{abstract}

Palabras clave: trashumancia, Andes chilenos, veranadas e invernadas, Pehuenco

Key words: trashumance, Chilean Andes, veranadas e invernadas, Pehuenco

El debate sobre la construcción del espacio no es un asunto nuevo en la disciplina geográfica. Lefevre (1974) planteó en su obra, que el espacio es un producto de la sociedad que se construye a partir de complejas interacciones entre dimensiones materiales, sociales e ideológicas. Bajo esta lógica, cada persona o colectividad puede construir un "espacio propio", el cual estará fuertemente marcado por creencias, prácticas, costumbres y formas de relacionarse con otros actores y agentes, reconociéndose, por tanto, una concepción del espacio como una integralidad multidimensional (Torres, 2016). De igual forma, Núñez, Arenas y Sánchez (2017:1), señalan que el espacio es el "resultado de un proceso de significación que solo adquiere visibilidad como construcción social, involucrando una carga vital de perspectiva temporal". De acuerdo a Lefebvre (1974), existen tres aspectos fundamentales en la construcción del espacio: (i) las prácticas espaciales, referidas a lugares concretos y las características de los conjuntos espaciales de cada formación social, (ii) las representaciones del espacio o el espacio concebido, vinculado a las relaciones de producción y al "orden" que imponen esas relaciones y, por lo tanto, al conocimiento, a los signos y códigos y (iii) los espacios de representación, los espacios vividos, que son simbólicos y a menudo marginales de la vida social.

Al observar las montañas como espacios construidos, estas pueden ser representadas y leídas a través de distintos elementos que las distinguen a lo largo del tiempo. Bailly (2013) señala que tradicionalmente, estas han sido presentadas como fronteras naturales, que permiten separar

Instituto de Ciencias Ambientales y Evolutivas, Universidad Austral de Chile, Valdivia. correo electrónico: carla.marchant@gmail.com Resultado del proyecto FONDECYT de Iniciación N¹1140493. La autora agradece a todos los miembros de la comunidad Pedro Currrilem, especialmente a su Lonkgo por su disposición a participar en este trabajo y por compartir sus conocimientos de la montaña y del pueblo pehuenche. Extiendo mi gratitud a Patricio Tenorio, Marcelo Hernández, Ana Jara y Daniela Caifil estudiantes tesistas de este proyecto de investigación, quienes colaboraron activamente en la recopilación de información. 
Estados-Nación y demarcar territorios, regiones y soberanías. Estas son también comúnmente consideradas como espacios objeto de conservación de la biodiversidad, o espacios de producción económica, según la interpretación disciplinaria que se esté considerando. Sin embargo, a partir de otras miradas como las ofrecidas por Núñez, Arenas y Sánchez (2013:15), la cordillera de los Andes y las fronteras pueden ser vistas "como sociabilidades cuya configuración es factible de ser historizada o enmarcada en una memoria colectiva que la explica". En este contexto y bajo una perspectiva geográfica, que intenta recoger la relevancia del giro cultural que la disciplina ha tenido en las últimas décadas (Lindón y Hiernaux, 2010), donde la geografía deja de considerarse como un saber estático y se interna en otras formas de construcción de la categoría espacial, como las hermenéuticas propuestas por Aliste y Núñez (2015), este artículo busca caracterizar y comprender como la práctica trashumante pehuenche realizada por la comunidad Pedro Currilem de Pehuenco en la comuna de Lonquimay, transforma a este espacio geográfico en un territorio, donde la experiencia existencial del habitar es clave y pilar de su devenir. Se entenderá entonces la trashumancia como una práctica social basada en el conocimiento ecológico local y una acción que significa y construye una representación de este territorio de montaña en el sur de Chile.

Para el pueblo pehuenche, de acuerdo a Huiliñir (2010), esta práctica posee una significancia económica, cultural y ambiental. Martínez (2015:100) agrega que desde la perspectiva territorial "esta es una forma de articulación que designa varias cosas por separado y todas a la vez. Así, por ejemplo, se usa para designar espacios, prácticas sociales y modos de producción". De acuerdo al autor, estas prácticas de "ancestralización" ayudan a fortalecer la territorialidad y la identidad de las comunidades. En este espíritu, el artículo busca contribuir a responder las siguientes preguntas: ¿Cuáles son las principales prácticas desarrolladas por la comunidad Pedro Currilem durante su viaje trashumante en Pehuenco? ¿Qué elementos distintivos, basados en el conocimiento ecológico local de la comunidad, emergen en este caso particular? ¿De qué manera estas prácticas se espacializan y se plasman en el territorio, construyendo y significándolo?

Para ello el texto se organiza de la siguiente manera: en primer lugar, se realiza una reflexión teórica sobre el desarrollo de la práctica trashumante y como ésta puede ser entendida como una práctica propia y distintiva de territorios de montaña, que genera una representación de estos espacios fuertemente vinculada al conocimiento ecológico local. Posteriormente, se presenta el abordaje metodológico de la investigación, este se realiza bajo un enfoque cualitativo que consideró para la recopilación de información, métodos como el mapeo colectivo, la aplicación de entrevistas semiestructuradas en profundidad con miembros de la comunidad y otros informantes clave, además de observación participante. A continuación, la información fue analizada y contrarrestada con la bibliografía pertinente. Los resultados obtenidos dan cuenta que la trashumancia implica una multiplicidad de prácticas tanto materiales como simbólicas, producidas gracias al conocimiento local del territorio y cargadas de intrínseco valor para la comunidad, elementos que lo transforman en un espacio vivido que solo puede comprenderse al observar sus especificidades.

\section{La práctica trashumante como una representación social de los territorios de montaña}

En su acepción más amplia, la trashumancia es definida por Pérez y Mateo (2011) como un sistema tradicional de manejo del ganado, el cual se remonta al periodo comprendido entre los años 
2000 y 4000 AC, característico de zonas montañosas con marcados climas estacionales como por ejemplo el centro y norte de Europa. González et al. (2012) complementan esta definición mencionando que su característica principal es el desplazamiento temporal del ganado a zonas altas destinadas al pastoreo de verano y a zonas bajas durante el invierno.

De acuerdo a la International Union for Conservation of Nature and Natural Resources, (IUCN) la trashumancia y la ganadería nómada ocupan entre 100 a 200 millones de personas y su extensión, se calcula en treinta millones de kilómetros cuadrados a nivel mundial (Mcgahey, 2014). Existen diversas formas de realización de la práctica trashumante; García (1990) señala que es posible identificar tres tipos de trashumancia considerando las trayectorias de desplazamiento:(i) trashumancia local, caracterizada por desplazamientos cortos, normalmente dentro de una misma unidad administrativa, (ii) trashumancia transtermitante con desplazamientos entre varios territorios administrativos próximos y (iii) la trashumancia regional que implica largos desplazamientos, mayores a 200 kilómetros. Una segunda dimensión relevante de la práctica es el sentido en que se desarrolla, dado que es posible identificar trashumancia vertical y horizontal. La trashumancia horizontal no implica cambio altitudinal para el uso de los pisos ecológicos como si ocurre en el caso de la trashumancia vertical.

En la Cordillera de los Andes es posible encontrar diferencias significativas entre las características de la trashumancia. En los Andes centrales, región conocida como puna o altiplano, comprendida por el oeste boliviano, el centro y sur de Perú, norte de Chile y noroeste argentino, la actividad se localiza en regiones semiáridas entre los 3.700 y 5.000 msnm e involucra camélidos (llamas, alpacas, vicuñas y guanacos), existiendo evidencias de su desarrollo desde la época del imperio Inca (Guerra, 2005). Por su parte, en los Andes del Sur la actividad se desarrolla en ambos lados de la Cordillera; en Chile entre los 600 y 1.200 msnm en las regiones de Bio Bio y La Araucanía y en Argentina desde el sur de la Provincia de Mendoza, hasta la provincia de Neuquén. En ambos casos esta actividad involucra ganado ovino, bovino, caprino y equino (Andaluz, Mérega y Palmili, 2006).

En Chile, la trashumancia ha sido abordada desde distintas enfoques y disciplinas científicas. Desde las ciencias naturales, destacan investigaciones vinculadas a aspectos botánicos (Hauenstein, 2002), de productividad ecológica y conservación (Ahumada et al., 1999). Por otro lado, desde las ciencias sociales, y considerando los planteamientos de Tomasi (2013) y Zusman et al. (2007), quienes concuerdan que la trashumancia es una muestra de una territorialidad basada en la movilidad, la que debe entenderse como una práctica social, se destacan una serie de estudios de corte cultural (enfoques antropológicos, históricos, geográficos) que describen las características propias y distintivas de la práctica. En el norte de Chile, destacan los aportes realizados por Núñez y Nielsen (2011) quienes abordan la movilidad atacameña histórica y pre-histórica; Aranda (1971) quien estudió la trashumancia en el norte chico; Schiappacasse y Niemeyer (1975) que trataron la trashumancia en el Valle de Camarones y las numerosas contribuciones realizadas por Molina sobre la movilidad de Collas y Atacameños en la Cordillera de Atacama (2004, 2010 y 2011). En uno de estos trabajos, Molina (2011) señala que esta práctica se inicia durante el tiempo colonial debido a las sequías que afectaban la zona, realizándose circuitos transfronterizos que abarcaban desde el noroeste argentino, San Pedro de Atacama, hasta Peine, último pueblo atacameño antes de iniciarse el despoblado hasta Copiapó. En la zona central, destacan los trabajos realizados por Guerra (2005) y Razeto y Suckel (2007) quienes describen las prácticas trashumantes de arrieros y ganaderos en el valle de Aconcagua y como estas pueden ser interpretadas como elementos constitutivos del paisaje cultural de la zona. 
Por su parte, en el centro-sur, el pueblo mapuche pehuenche, quienes antes de la ocupación española habitaban el territorio de ambas vertientes de la Cordillera de los Andes entre Talca y Lonquimay (Molina y Correa 1996, 1997), adquiere e internaliza este conocimiento como una nueva práctica agroganadera, una vez que los españoles ocuparon el territorio indígena cordiIlerano del centro y sur de Chile a finales del siglo XVI (Villalobos, 1989; Ugarte, 1997; Bengoa, 2000; Torrejón 2001). Bello (2011) realiza en su obra Nampülkafe (el que viaja mucho al extranjero), una acabada descripción de las movilidades transfronterizas entre el Ngulumapu (Araucanía) y el Puelmapu (Pampa Argentina) realizadas por el pueblo mapuche-pehuenche durante el siglo XIX y principios del XX. Otros aportes relevantes desde la Geografía en la materia, son los ofrecidos por Sepúlveda (2012), en su trabajo sobre el territorio mapuche en Chile, Huiliñir (2010 y 2015) quien describe la movilidad territorial articulada a través de los senderos Pehuenches en Cauñicú y El Barco en el Alto Bio Bio. Asimismo, Martínez (2015) profundiza sobre el caso de la comunidad pehuenche de Quinquén en Lonquimay.

\section{La práctica de la trashumancia en contexto mapuche - pehuenche}

La trashumancia en el sur de Chile es desarrollada tanto por el pueblo pehuenche como por colonos chilenos y extranjeros de Europa. Estos últimos llegaron a la zona principalmente en el contexto del proceso de colonización impulsado por el Estado chileno durante la segunda mitad del siglo XIX a través de la Agencia General de Colonización e Inmigración para Europa, creada en 1882 (González y Bernedo 2013), lo que significó el despojo de los denominados territorios ancestrales y la relocalización de los mapuches en reducciones en base a la entrega de Títulos de Merced, originando minifundios comunitarios (Correa, Molina y Yánez 2005), significando este acto, su incorporación jurídica al Estado de Chile. Este proceso se reforzó durante el período conocido como contrarreforma agraria ocurrida durante la dictadura militar (1973 - 1990), cuando se inicia un proceso de erradicación de las comunidades indígenas, a través del D.L. No 2.568 sobre División de las Comunidades Indígenas y se entregan tierras a través de títulos individuales de dominio. Este proceso condujo a profundas transformaciones en las prácticas de habitar el espacio por parte de las comunidades. Al respecto la Comisión Verdad Histórica y Nuevo Trato (2003:46) señala que:

“La división de las comunidades no respetó los espacios comunes que por siglos han existido en la tierra mapuche (bosques, veranadas, etc), los que constituían, además, espacios de significativa importancia para la economía agraria del mapuche. Tampoco fueron respetados espacios fundamentales para el desarrollo de la cultura mapuche (sitios sagrados, canchas de nguillatún, etc)".

Lo anterior ha tenido consecuencias en aspectos esenciales de los modos de vida y el habitar de las comunidades pehuenches. Entre estos cambios destacan las nuevas formas de división del trabajo entre hombres y mujeres, la promoción de la migración desde los espacios rurales a las ciudades, debido a las limitadas opciones existentes en las denominadas reducciones, la pérdida de redes y formas de asociatividad y colaboración, además de la profundización del desarraigo cultural. Este proceso consolida además una denominada "deuda histórica" (Foerster 2002) del 
Estado chileno con el pueblo mapuche, quienes abogan por su derecho a la autodeterminación como pueblo y la soberanía territorial, aspectos considerados una legítima reivindicación.

En la región de la Araucanía, y desde la perspectiva del Estado, existen, de acuerdo a Hauenstein (2002), trece áreas reconocidas legalmente como veranadas; de éstas, ocho se ubican en la comuna de Lonquimay, abarcando un total de 119.000 hectáreas, distribuidas a lo largo del límite fronterizo. Administrativamente, la práctica trashumante como actividad productiva en Chile, es regulada por el Servicio Agrícola Ganadero (SAG), entidad encargada del control fitosanitario en zonas fronterizas. De igual manera, el Ministerio de Bienes Nacionales (MBN) es responsable de otorgar los permisos de uso de los terrenos fiscales en los cuales se desarrolla la actividad, normalmente a través de concesiones que se entregan a comunidades organizadas, por ejemplo, a través de comunidades indígenas o comités de campesinos, como es el caso de la organización de veranadas colonas de Pulul, al norte de la comuna de Lonquimay. Asimismo, desde agosto del año 2016 se encuentra en tramitación en el Senado, una modificación a la ley de áreas silvestres protegidas del Estado, la que busca normar el desarrollo de la actividad de veraneo en estos territorios, otorgando la potestad de autorización de uso y paso a las direcciones regionales de la Corporación Nacional Forestal (CONAF) (Gobierno de Chile 2016).

\section{La práctica trashumante y el conocimiento ecológico local: interacciones entre naturaleza y cultura}

El desarrollo de la trashumancia en las áreas montañosas requiere de un conocimiento profundo de las características físicas del entorno en que se producen: mallínes, lagos y ríos, pampas, bosques y pinalerías, poseen características específicas en cada lugar, por lo tanto la trashumancia no puede ser vista como un fenómeno homogéneo. En este sentido, es posible considerar a la práctica trashumante como una actividad basada en el conocimiento ecológico local de los pueblos y colectividades que la desarrollan; este es un tipo de conocimiento no formal, definido por Berkes, Colding y Folke (2000:1251) como "un cuerpo acumulativo de conocimientos, prácticas y creencias que evolucionan a través de procesos adaptativos y que es transmitido mediante formas culturales de una generación a otra acerca de las relaciones entre seres vivos, incluyendo los seres humanos, y de los seres vivos con su medio ambiente".

A lo anterior, Reyes (2009) añade que este conocimiento es de carácter acumulativo y dinámico, que surge de las experiencias prácticas y de la capacidad de adaptación al cambio. Asimismo, el conocimiento ecológico tradicional es importante para las sociedades indígenas porque es parte de su identidad cultural, la cual se plasma en el territorio. En este contexto, es importante entender la cosmovisión pehuenche del territorio, esta difiere de la concepción occidental, donde Estado y territorio son elementos constitutivos básicos de un proyecto de nación y este último es una expresión de la espacialización del poder y de las relaciones de cooperación o conflicto que de ellas se derivan (Montañez y Delgado 1998). Dado lo anterior, resulta más apropiado acercarse al entendimiento de la dimensión espacial del pueblo pehuenche haciendo alusión al concepto de etno-territorio, el cual es definido por Molina (1995:113) de la siguiente manera:

"Los etno-territorios constituyen una categoría que da cuenta de los espacios habitados por pueblos indígenas o una parte de éstos, que poseen por característica, encontrarse delimitados 
por hitos geográficos reconocidos socialmente por una o más agrupaciones de una misma etnia o de otra distinta. Estos territorios son valorizados por los indígenas, al asignarle un contenido político, económico, social cultural y religioso".

En este contexto, es posible entender la trashumancia pehuenche como una práctica que construye una representación etnoterritorial, dado que cada una de las actividades que la componenen, significan el espacio con un contenido y de forma específica. El territorio es, como lo plantea Ther, (2012) no solo el soporte biofísico de cada actividad humana, sino que también una imbricación de formas y procesos que se caracterizan por el sentido identitario y la exclusividad. En este sentido, la forma en que se habita cada espacio de montaña, se relaciona con los medios, elementos y motivaciones para estar y permanecer en él. Asimismo, esta relación implica una forma específica de interacción con lo ambiental, dando cuenta de una territorialidad particular, construida colectivamente. Lo anterior, es entendido por Giménez (2004) como "una representación social del espacio, que une al interior y separa del exterior a los habitantes de una localidad". Siguiendo esta idea, el territorio de montaña donde se desarrollan las pácticas de veranada e invernada, se transforma en un espacio significado material y simbólicamente. Dado lo anterior, el desarrollo de la trashumancia puede considerarse una acción transformadora, considerando los postulados de Lefebvre (1974) y parafraseando a Ther (2012), que produce un "espacio vivido".

\section{Metodología}

La metodología utilizada tiene un enfoque cualitativo. Durante marzo de 2015 y enero de 2018 se trabajó con quince miembros de la comunidad Pehuenche Pedro Currilem (10 hombres y 5 mujeres; las edades de los participantes fluctuaron entre los 20 y 70 años) del sector de Pehuenco en la comuna de Lonquimay.

Para recabar información sobre la práctica trashumante, se utilizaron distintas técnicas de recolección de datos, a saber: (i) observación participante en actividades organizadas por la comunidad, como fiestas costumbristas locales (fiesta costumbrista Pehuenche; fiesta del Piñón), (ii) visitas a terreno a la veranada con miembros de la comunidad; (iii) ejercicios de mapeo colectivo basado en la metodología propuesta por el colectivo de cartografía crítica Iconoclasistas (Risler y Aler 2013). En este contexto se desarrollaron cinco sesiones de mapeo participativo con el longko y los miembros de la comunidad quienes fueron invitados por medio de una convocatoria abierta. En tres sesiones de mapeo se trabajó con un guión temático de preguntas relacionadas la práctica trashumante propiamente tal y a la caracterización del territorio, el cual fue estructurado considerando aspectos culturales, históricos y sociales, económicos y ecológicos (Tabla 1). El tercer y cuarto mapeo se orientó a identificar conocimientos ecológicos locales asociados a las prácticas, actividades y toponimia de lugares previamente registrados en el mapa. Finalmente, para completar la información espacial recopilada en las etapas anteriores, se realizaron (iv) entrevistas semiestructuradas en profundidad con informantes claves de la comunidad, a saber: el longko, y el werkén en la comunidad y dos lawentuchefes. En estas instancias se utilizó una pauta de preguntas flexible, la cual permitió al entrevistador ahondar en aspectos prácticos e inmateriales de la trashumancia.

Finalmente, se utilizaron distintas estrategias para analizar la información. Para el caso del mapeo participativo, los resultados obtenidos de las categorías del guión temático se clasificaron según (i) tipo de prácticas y acciones asociadas y (ii) espacios significativos, los cuales se espa- 
cializaron en la cartografía del territorio. El mapa resultante de las jornadas fue rectificado con la comunidad para consensuar la información plasmada en él. Por su parte, las entrevistas fueron transcritas y sometidas a un análisis a través de la categorización de los contenidos utilizando el software Atlas.ti. lo cual permitió identificar en los relatos, distintos conocimientos ecológicos locales asociados a las prácticas, acciones y lugares resultantes del paso anterior. Estos resultados fueron complementados con antecedentes provenientes de la observación participante y de la revisión bibliográfica. Cabe destacar que, para resguardar los aspectos éticos de la investigación, la información utilizada en este estudio fue autorizada para su divulgación por los participantes, a través de la firma de un consentimiento informado de participación.

Tabla 1

Guión temático sesiones de mapeo colectivo

\begin{tabular}{|c|c|}
\hline Aspectos socioculturales & Aspectos históricos \\
\hline $\begin{array}{l}\text { Composición grupo familiar } \\
\text { ¿Cuántas personas realizan la veranada? } \\
\text { ¿Cuántos animales suben? (especificar) }\end{array}$ & $\begin{array}{l}\text { Propiedad de la tierra } \\
\text { ¿Puede delimitar el área de veranada? O } \\
\text { ¿Considera esta delimitación propuesta } \\
\text { correcta? }\end{array}$ \\
\hline $\begin{array}{l}\text { Rutas y flujos } \\
\text { Identifique el trayecto (sendas) que usted nor- } \\
\text { malmente hace con sus animales. ¿Cuántos } \\
\text { kilómetros son? ¿Siempre se realiza el mismo } \\
\text { trayecto? ¿Cumplen las mismas funciones? } \\
\text { ¿Existen diferencias en el estado de las hue- } \\
\text { Ilas? (Sectores en mal estado, peligrosos, etc.) } \\
\text { ¿Cuántos días dura el trayecto realizado? } \\
\text { ¿Cuántos animales se movilizan normalmente } \\
\text { en un recorrido? }\end{array}$ & $\begin{array}{l}\text { ¿Qué hitos reconoce para esta delimitación? } \\
\text { (cerros, ríos, quebradas, etc.) } \\
\text { Pensando en el pasado, ¿hay cambios en las } \\
\text { superficies que usted utiliza de la veranada? } \\
\text { (más grande/pequeña en comparación al pa- } \\
\text { sado) ¿A qué se debieron esos cambios? } \\
\text { ¿A quién pertenecen estos terrenos? (Indagar } \\
\text { en las relaciones inter o intracomunidad) }\end{array}$ \\
\hline $\begin{array}{l}\text { Toponimia } \\
\text { Nombre e identifique los sectores que tiene la } \\
\text { veranada ¿Tienen algún significado estos nom- } \\
\text { bres? } \\
\text { ¿Reconoce estos lugares a partir de las } \\
\text { fotografías? }\end{array}$ & $\begin{array}{l}\text { ¿Existen zonas de acceso difícil o problemático } \\
\text { debido a que la tierra es privada? Puede } \\
\text { mostrarlos en el mapa }\end{array}$ \\
\hline $\begin{array}{l}\text { Calidad ambiental percibida } \\
\text { ¿Hay lugares con mejores/peores pastos? ¿Hay } \\
\text { lugares con mejores/peores bosques? Puede } \\
\text { identificarlos }\end{array}$ & \\
\hline $\begin{array}{l}\text { Hitos } \\
\text { Identifique estaciones de: descanso, aloja- } \\
\text { miento (fijo/alternado), alimento para los ani- } \\
\text { males, corrales, otros... } \\
\text { ¿Existen en el trayecto lugares con significancia } \\
\text { simbólica? Por ejemplo: sagrados/evitados }\end{array}$ & \\
\hline
\end{tabular}




\begin{tabular}{|c|c|}
\hline Aspectos socioculturales & Aspectos históricos \\
\hline $\begin{array}{l}\text { Diferencias entre prácticas ancestrales y } \\
\text { prácticas actuales } \\
\text { ¿Observa cambios entre la forma que se hacía } \\
\text { el traslado de los animales antes en relación a } \\
\text { ahora? } \\
\text { Amenazas externas } \\
\text { ¿Considera que existen situaciones que } \\
\text { amenacen el uso de las veranadas y la } \\
\text { actividad? }\end{array}$ & \\
\hline Aspectos ecológicos & Aspectos económicos \\
\hline $\begin{array}{l}\text { Erosión } \\
\text { ¿Puede identificar lugares donde hay menos o } \\
\text { no hay pastos? } \\
\text { ¿Sabe por qué se ha acabado el pasto allí? } \\
\text { Biodiversidad } \\
\text { ¿Puede reconocer plantas o árboles } \\
\text { representativos de las veranadas? } \\
\text { ¿Cuáles son de uso: medicinal, comestible/ } \\
\text { leña/cerco? } \\
\text { Problemas ambientales } \\
\text { ¿Hay alguna situación (del ámbito natural) } \\
\text { que usted considere amenace el uso de la } \\
\text { veranada? }\end{array}$ & $\begin{array}{l}\text { Piñoneo } \\
\text { ¿Puede identificar lugares de recolección de } \\
\text { piñones? (antiguos y nuevos) } \\
\text { Ganado } \\
\text { ¿Cada cuánto tiempo se rota el ganado? } \\
\text { ¿Existe algún manejo técnico en las veranadas? } \\
\text { Puede describirlos } \\
\text { Recursos madereros } \\
\text { ¿Puede identificar sectores de extracción y/o } \\
\text { acopio de leña } \\
\text { Turismo } \\
\text { ¿Puede identificar rutas o lugares donde se } \\
\text { hagan actividades turísticas? Por ejemplo } \\
\text { cabalgatas, paseos, etc. }\end{array}$ \\
\hline
\end{tabular}

Fuente: elaboración propia

\section{La práctica trashumante en Pehuenco}

La comunidad Pedro Currilem está ubicada en la localidad de Pehuenco, al sur de la comuna de Lonquimay, a 180 kilómetros de Temuco, capital regional de La Araucanía y a 25 kilómetros del paso fronterizo "Pino Hachado". Pehuenco se localiza cercana a dos áreas de protección natural administradas por la Corporación Nacional Forestal (CONAF), desde Pehuenco hacia el Noreste, la Reserva Nacional Alto Biobío y desde Pehuenco hacia el Suroeste, la Reserva Nacional Lago Galletué. En cuanto a la toponimia del lugar, Pehuenco significa "agua de araucaria" (pehuén "araucaria"-co "agua"). Este sector de montaña (mawida), desde la perspectiva del uso que sus habitantes hacen del territorio, puede subdividirse en dos: Pehuenco Alto y Pehuenco Bajo. En invierno la comunidad se establece en Pehuenco Bajo donde tienen sus residencias fijas, además de hitos de significancia cultural, como la Escuela Epu-Pewen, el Centro Cultural Pehuenche Kimun, el cementerio (eltuwe), la cancha donde se celebra el nguillatun y se ubica el rehue de la comunidad. 
Pehuenco Bajo es también el lugar de acceso a la movilización a través de la ruta internacional G-181, que conecta con otros centros poblados.

En la época estival, es decir al inicio de la veranada, la población se traslada a Pehuenco Alto, donde se ubican los puestos de pastoreo (rukos) para la realización de la actividad. De acuerdo a información provista por el Servicio Agrícola y Ganadero (SAG), la extensión de esta veranada es de 7855 hectáreas. Esta cifra corresponde al territorio reconocido legalmente para el uso, pero no implica dominio o propiedad exclusiva de esta extensión de tierra por parte de la comunidad indígena Pedro Currilem, ya que en este espacio delimitado por SAG existen otras 5 comunidades indígenas reconocidas por CONADI, con quienes se comparte el territorio, a saber: Pehuenco Bajo, Pehuen Ko Bajo, Pehuenco Alto, comunidad Gregorio Nehuen, y la comunidad Lof Lelfun Gregorio Nehuen.

La comunidad se encuentra inscrita desde el año 2001 en el Registro de Comunidades y Asociaciones Indígenas de la CONADI y posee personalidad jurídica vigente, su representación legal recae en su presidente, el longko N.R.C². El longko es la máxima autoridad política y religiosa de una comunidad o Lof. La Comunidad Pedro Currilem debe su nombre a uno de los longkos que habitó en este territorio ancestralmente y está compuesta por 56 familias, alcanzando un total de aproximadamente 300 personas. La propiedad de la tierra en esta veranada proviene de parcelaciones realizadas en el año 1985, en el contexto de transferencias de tierras fiscales a comunidades mapuches. A través de la ley de saneamiento de tierras impulsada por la dictadura, el Ministerio de Bienes Nacionales transfirió al Departamento de Asuntos Indígenas del Instituto de Desarrollo Agropecuario, la facultad de subdividir y entregar las tierras fiscales ocupadas por comunidades mapuches (Comisión Verdad Histórica y Nuevo Trato 2003). Es así como el predio "Grupo Indígena Levinao Zúñiga", de una extensión de 13.463 hectáreas fue subdividido y entregados a propietarios individuales en formato de hijuelas (aproximadamente 100) entre las familias de la zona. Legalmente, la comunidad Pedro Currilem posee 2100 ha. Aproximadamente, repartidas en hijuelas de, en promedio 0,5 hectáreas (superficies registradas entre 0,2 ha y $1 \mathrm{ha}$ ).

\section{La práctica trashumante y las acciones que la componen y significan}

\section{Veranear}

De acuerdo a las entrevistas, el inicio de la veranada no tiene una fecha fija y está condicionada más bien a aspectos climáticos que incidirán en la localización de los puestos o rukos de veraneo. Los rukos son un tipo de refugio artesanal construido para guarecer a los veraneantes durante el trayecto trashumante, están construidos con maderas y ramas provenientes de la recolección de leña muerta en las inmediaciones; algunos poseen corrales para el mejor control del ganado (Figura 1). Cada ruko pertenece a un miembro de la comunidad; en Pehuenco se contabilizaron 24, repartidos en las inmediaciones de las huellas que circundan los esteros del cajón Pehuenco y

Para dar cumplimiento a aspectos éticos de la investigación, se entregan solo las iniciales para resguardar la identidad de los participantes del estudio. 
del cajón Tralilhue (Figura 4). Aquellos miembros de la comunidad que tienen sus puestos o rukos más cerca de su residencia fija en Pehuenco Bajo, comienzan a subir en octubre para aprovechar la mayor cantidad de meses en Pehuenco Alto. Así lo relata uno de los entrevistados (masculino, 60 años comunicación personal 2015)

"La familia entera arriba, saliamos en noviembre, diciembre hasta abril, marzo cuando empezaban las nevazones, recolectando las hierbas, recolectando los piñones, enseñándole también otra cultura a los chicos, con sus animalitos, arreando sus chivitos, vivir en unos rucos no más, allá no hay comodidad, hay rucos no más".

El resto de los miembros de la comunidad lo hace entre diciembre y enero. Lo anterior se debe a que los puestos más alejados se encuentran a mayor altura (entre los 1300 a 1700 msnm) y que, en condiciones climáticas normales, la nieve no permite establecerse en los puntos de pastoreo tempranamente. El período de veraneo dura entre 4 a 6 meses. El inicio de la invernada en Pehuenco está marcada por las primeras heladas del año, por lo tanto, este es un indicador para el inicio del arreo de animales hacia las partes bajas del valle, lo que ocurre entre fines de marzo y mayo.

Figura 1

Puesto de veraneo y corral para animales.
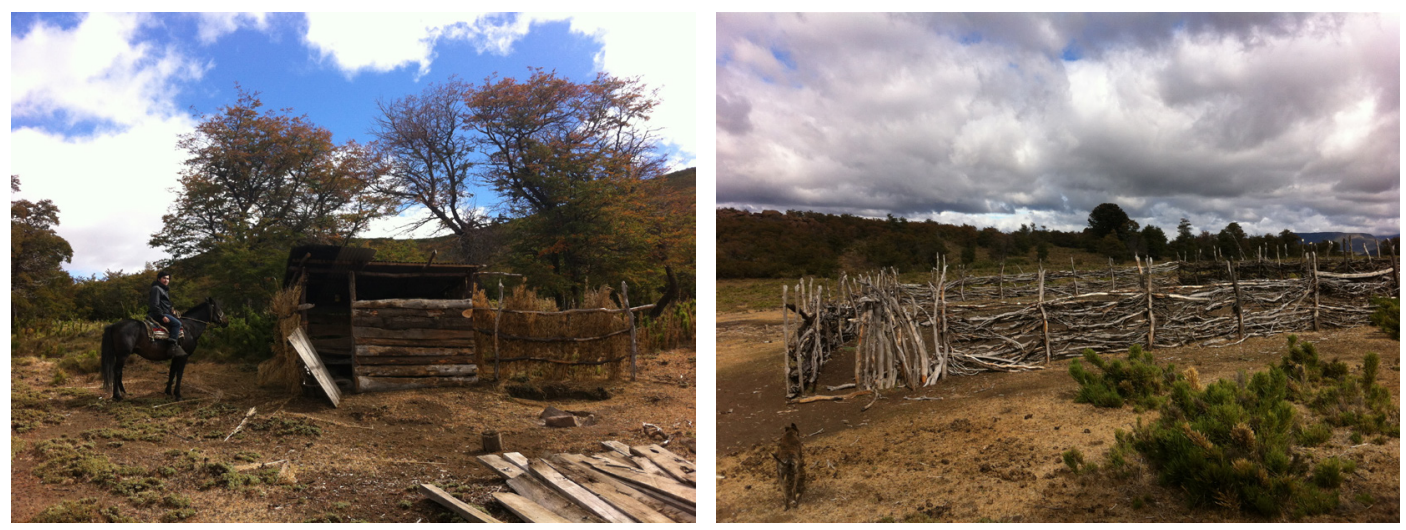

Fuente: Autora, 2015

\section{Arrear y manejar los animales}

El arreo corresponde a la práctica del traslado del ganado desde la invernada (específicamente de galpones ubicados alrededor de las viviendas y del centro cultural en Pehuenco bajo) a la veranada o viceversa; esta actividad se realiza en distintas etapas y tiempos dependiendo el tipo de ganado que se traslade y también de la distancia entre la invernada y veranada. El traslado se realiza por medio de huellas de arreo o caminos de ripio, en grupos de hombres, normalmente a caballo, sin ayuda de medios mecánicos (como por ejemplo vehículos, práctica observada en otras veranadas de la región). Cada familia sube a la montaña (mawida) alrededor de 15 a 20 animales grandes (bovinos, equinos); en cuanto a animales menores (ovinos, caprinos) la cantidad es relativa; en el 2015 los participantes mencionaron que estos ejemplares menores alcanzaron 
un total de 60 (Figura 2). Sin embargo, no es posible establecer un número exacto de animales; según estadísticas del Servicio Agrícola y Ganadero (SAG), el total de animales rondaría las 2000 cabezas en este año. En cuanto al tiempo que tarda el trayecto hasta los lugares de pastoreo, desde el inicio de la veranada hasta los puntos más lejanos en Laguna Escondida y Piedra Sinchona alcanzan los 23 y 25 kilómetros respectivamente, para lo cual los animales grandes pueden demorar un día de ruta y los animales pequeños dos días.

Figura 2

Animales menores en la invernada.

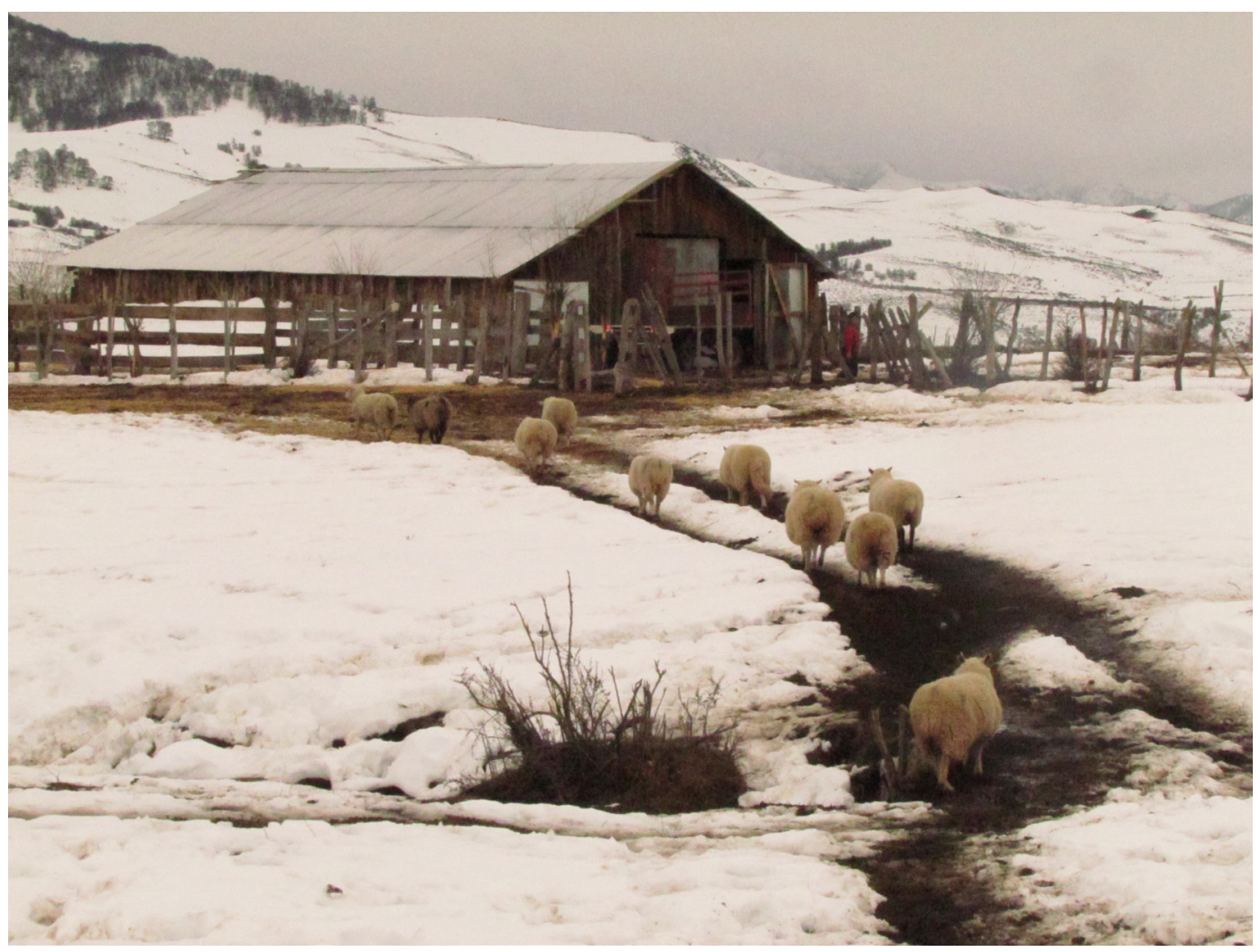

Fuente: Autora, 2015

En cuanto al manejo del ganado, este corresponde a una serie de actividades controladas por el Servicio Agrícola y Ganadero y realizadas en conjunto con los veraneantes; ejemplos de ello son los controles sanitarios abocados principalmente a la incrustación de areteos y al control de fiebre aftosa. Así lo relata un entrevistado (masculino, entre 20 y 40 años, comunicación personal, 2015).

"A si, están todas marcadas y señaladas [refiriéndose al ganado]. Y el SAG acá los aretea antes de poderlos subir... ellos vienen aretean y después se supone que dan la subida... de repente igual se demoran y como son hartos animales y poco personal así que la gente igual si tiene que subir sube no más, y después van a aretear a las veranadas de repente." 
A estas actividades se añade el manejo de las praderas, lo cual implica establecer prioridades al momento de subir los animales para reducir la erosión del suelo y aprovechar más eficientemente las pasturas nuevas de coironales (Festuca scabriuscula), la cual es la especie predominante. Los animales mayores pastorean primero, esto permite que ellos se alimenten con pasto nuevo y fertilicen el suelo; luego ascienden los menores, esto dado que los caprinos son los que causan mayor erosión del suelo, sobre todo en las partes más altas y de mayor pendiente, por lo cual su manejo implica más preocupaciones a los veraneantes. Esta alternancia permite el abastecimiento de forraje para todo el rebaño, preparándolos para el invierno. Así lo relata el mismo entrevistado:

"En primavera paren todos los animales, ahí se les da el último forraje que va quedando y un poco de lo que queda aquí, y en cuanto se pueda se sacan para arriba. Se llevan para arriba y acá arriba engordan, y después ya, se supone que bajan con más reserva. Más gordos, más grasa. Y ahí, ya en el invierno se guarda el forraje y todo."

Otro aspecto importante mencionado en las entrevistas, que se relaciona con la calidad y disponibilidad de las praderas de pastoreo, corresponde a la recurrencia de eventos climáticos extremos, los cuales según la percepción de los habitantes, se han vuelto más recurrentes en el último tiempo. Al respecto un entrevistado (masculino, 60 años comunicación personal 2015), hace referencia a los episodios de sequía extrema que se han vivido en la zona en los últimos cinco años y como esto afecta la economía local, relata:

"El año pasado fue un año malo. El pasto estuvo malo arriba, los animales bajaron flacos y entraron flacos al invierno. Después se preñan, y el animal, para estar bien siempre necesita las mejores condiciones para después dar a luz. Entonces, esas son las consecuencias cuando vienen muy secos los años. Después ya los animales flacos se te empiezan a morir, empiezan a mal parir, y ahí ya comienzas a irte en pérdida más que en ganancia. Entonces influye harto de como este el pastoreo arriba".

A esta compleja situación se añadió en 2015 una dificultad extra producida por la erupción del volcán Calbuco, la cual dejó una espesa capa de cenizas en el suelo, provocando como consecuencia un bajo desarrollo de las praderas de la veranada. Asimismo, los problemas de bajo peso de los animales implicaron la necesidad de compra de forraje extra y menores ganancias en las ferias de venta de ganado que se realizan en Lonquimay y en otras comunas cercanas como Victoria.

\section{Piñonear}

Una segunda práctica relevante durante el desarrollo de la veranada es el piñoneo, realizado principalmente por niños y mujeres en las pinalerías o bosques de Araucarias (pewento). El piñoneo forma parte de las actividades predominantes debido a su relevancia económica y sociocultural, además de ser la base de la alimentación tanto humana, como del ganado doméstico. Sin embargo, esta actividad posee un profundo significado social y cultural que va más allá de la dimensión económica, ya que implica también el desarrollo de trabajo colectivo, fomenta la cooperación intergeneracional y contribuye a la cohesión de la comunidad. Tal como lo hace notar un entrevistado, es parte del patrimonio inmaterial que permite la continuidad de sus tradiciones. 
Al respecto de la práctica un entrevistado (masculino, 60 años, comunicación personal 2015) comenta:

"Se piñonea en la pampa Cayulafquén, es una pampa, una meseta en donde salen muchos piñones, eso es algo que no se ha perdido, que después lleguen todos en común y se recojan los piñones en las veranadas, ahí están todos igual unidos. Pero casi todos tienen, ya, cada uno sabe hasta dónde llega su campo ¿cierto?. Y ahí piñonean...y hay algunos que no tienen pinos. Entonces ese es el problema, todavía hay una consideración que de repente, que el que tiene pino al que no tiene pino, le convida al vecino".

Figura 3

Pinalerías o bosques de Araucaria.

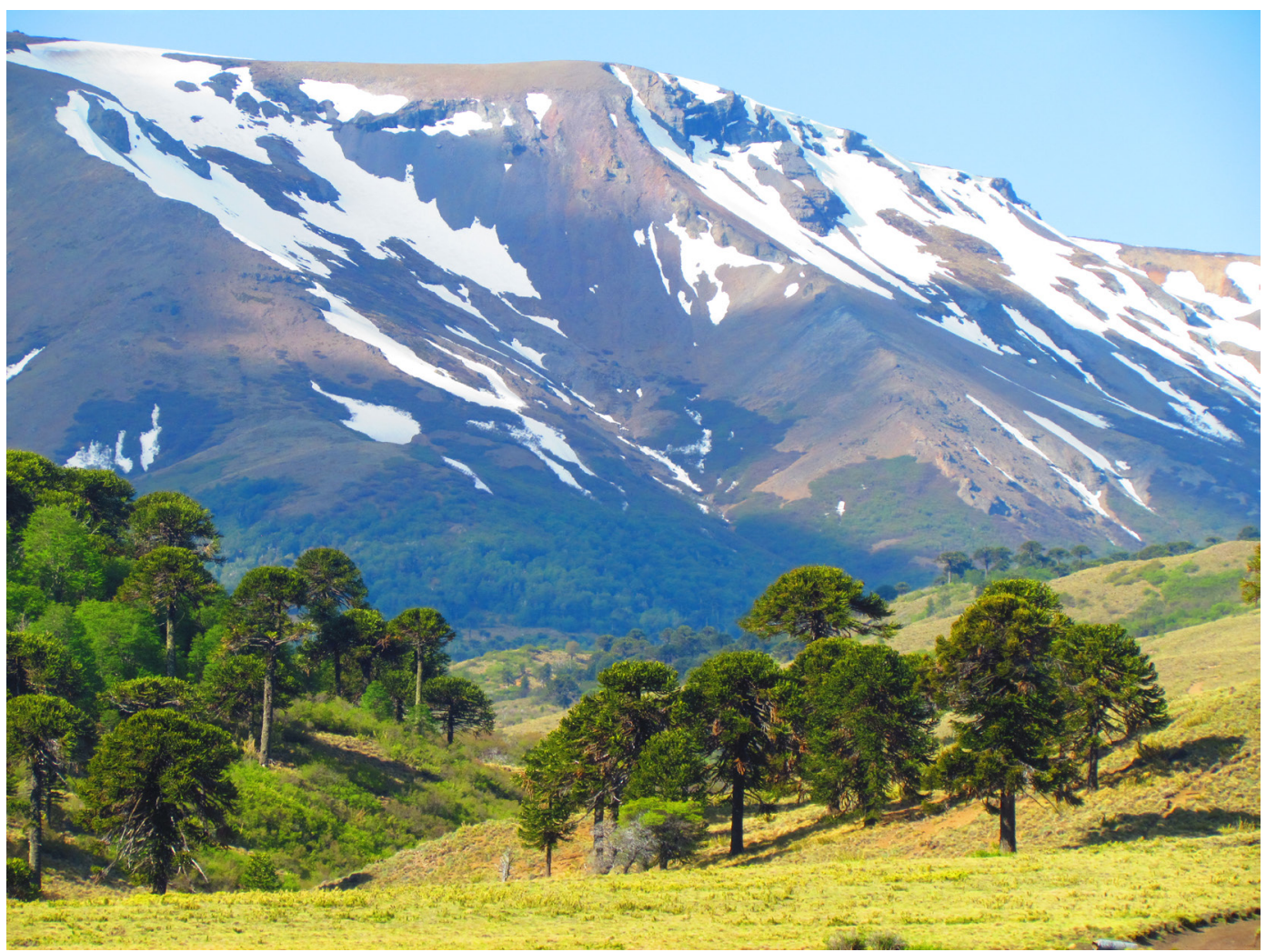

Fuente: Autora, 2015

Complementando el relato del entrevistado, se destaca que el piñoneo se realiza en primera instancia en las pinalerías aledañas a los hogares, en las hijuelas particulares de la familia en la invernada o bajos (también conocidos como pülom). Una vez concluido este, se continua en los bosques de araucaria en las veranadas, en tierras que tienen un uso colectivo (Figura 3). La colecta se realiza tomando los frutos femeninos desde el suelo, con las manos y cortando su tallo; sin embargo, cuando se requiere apresurar el proceso se recurre a otros procesos, tales como sacu- 
dir el árbol para provocar la caída de ganchos con los frutos o, en casos extremos, trepar el árbol. Sin embargo, esta práctica no es habitualmente desarrollada debido a los riesgos que implica. Asimismo, tal como mencionan Tacón et. al (2000) el trepar o zamarrear el árbol son prácticas mal vistas por las comunidades Pehuenches, por lo cual no se realizan habitualmente.

En cuanto a los volúmenes de producción, los entrevistados de la comunidad Pedro Currilem, señalan que estos son variables, dependiendo si la cosecha se produce en un buen o mal año. Dado esto, no pudieron mencionar un número exacto de sacos o kilos recolectados en su última cosecha, ya que los rendimientos varían por familia. Al respecto, cabe mencionar de manera referencial lo señalado por Tacón, Fernández y Ortega (2000) quienes para el caso de la comunidad Pehuenche de Quinquén, señalaron que, en un año malo, una familia pequeña podría cosechar entre 5 a 6 sacos y en uno muy bueno entre 60 y 100. La producción en esta comunidad es utilizada principalmente para el autoconsumo; en segundo lugar, para la venta a intermediarios y solo como producto fresco, ya que no lo procesan. También se seleccionan semillas que pueden ser guardadas (bajo tierra) y utilizadas para procesos de restauración de la especie en casos de emergencia ${ }^{3}$.

\section{Recolectar productos madereros y hierbas medicinales}

La extracción de leña en esta veranada corresponde principalmente a leña seca o muerta de Araucaria y Ñirre, en bajos volúmenes. Esta actividad se desarrolla principalmente en los sectores Mallín Seco y Mallín Largo, los cuales son bosques que tienen un uso comunitario. Esta leña es utilizada principalmente para la construcción de los rukos y para calefacción de los hogares. También se recolecta el picoyo, el cual es un gancho seco de araucaria muerta que contiene una alta cantidad de resina cristalizada que al caer es utilizado para la elaboración de artesanías. Así lo relata un entrevistado (masculino 20-40 años, comunicación personal, 2015)

"En realidad en la veranada esta la madera así, pero uno tiene que ir viendo lo que hay... es re poco lo que se voltea, casi siempre es lo que está seco y lo que está en el suelo. Y después lo que se ocupa harto acá igual es el picoyo, para hacer artesanía, para hacer leña".

Por otro lado, la recolección de hierbas medicinales tiene un significado práctico y espiritual. Los veraneantes describen que existen dos sectores diferenciados donde se desarrolla la recolección; (i) en las tierras secas y arenosas de sectores altos, donde se encuentran especies como la Paramela (Adesmia emarginata), el Quinchamalí (Quinchamalium chilensis) y Ñanco (Linum chamissonis), y (ii), sectores bajos, húmedos, conocidos como mallines, donde se recolecta principalmente Apio panul (Apio Panul). Con respecto a su uso, Bragg et al. (1986) señalan que estas hierbas son usadas por mujeres, machis y por aquellos miembros de la comunidad que tienen conocimientos sobre el uso médico de las hierbas (lawuentuchefes). Las formas de uso de estas hierbas varían entre preparaciones comunes como infusiones, cataplasmas, friegas o lavados; generalmente se guardan en seco y son usadas tanto para medicina humana como veterinaria.

\footnotetext{
Lo anterior es recalcado por el Longko, quien señaló que son los propios pehuenches quienes poseen los conocimientos sobre el piñon en sus distintas etapas y usos. Este es un conocimiento relevante que debiese ser considerado en procesos de restauración ecológica; cabe mencionar el ejemplo del proceso de restauración de bosques de Araucaria realizado tras el incendio de la Reserva Nacional China Muerta en 2015, donde comunidades pehuenches han desarrollado viveros utilizando sus conocimientos para el proceso de restauración.
} 


\section{Transferir el kimun}

Una de las actividades simbólicas más relevantes de la práctica trashumante, es la posibilidad que ésta otorga para reunir a distintos miembros y generaciones de la comunidad; en estas instancias se transmite de manera oral, por parte de los mayores, los aspectos más relevantes de la cosmovisión pehuenche a jóvenes y niños, se comparten relatos que permiten comprender como se interpreta el mundo, la vida y la significancia de los distintos lugares que transforman la trashumancia en un territorio vivido. En este sentido, el veranear es una oportunidad de vivir la naturaleza, entendiendo la especificidad de cada componente de ella. En la figura 4 se representan aquellas prácticas materiales que componen y significan este territorio.

Figura 4

Mapa representación de prácticas trashumantes en Pehuenco.

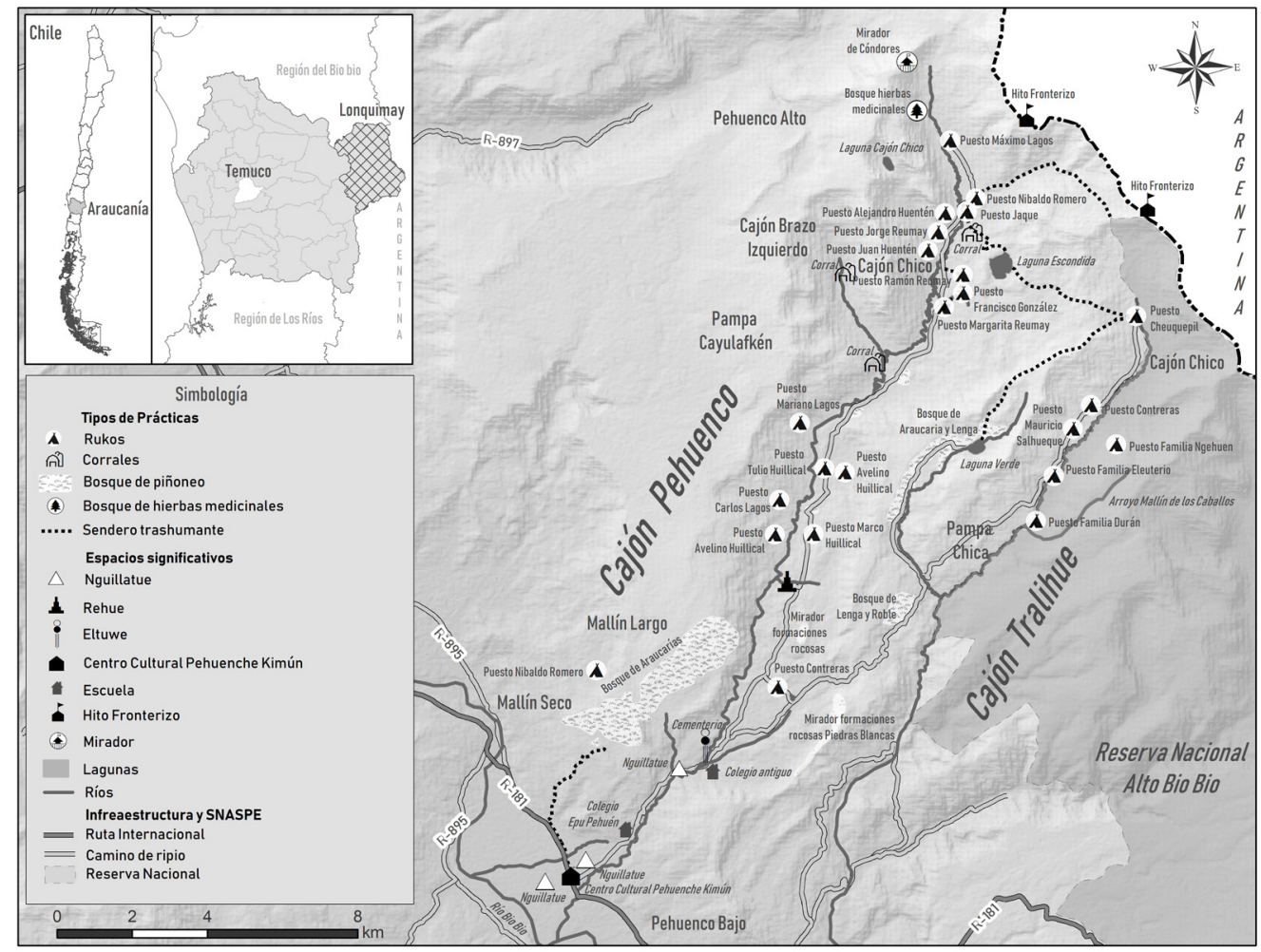

Fuente: elaboración propia

En este sentido, el bosque, el río, la laguna o la montaña, cuentan con un ngen, o espíritu, cuya función es dominar, disponer y resguardar lo que le es propio (Grebe 1993). Asimismo, el veranear entrega al longko y a la comunidad la posibilidad de nutrirse del newen (energía) de la naturaleza, siendo este aspecto una de las implicancias simbólicas más relevantes de la práctica. Sobre estos dos aspectos, el entrevistado (masculino, 60 años, comunicación personal 2015) señala: 
"En todos lados existen los ngen, los lugares sagrados, los rayenko, los winkul, todos los lugares tienen su ngen, eso es respetable para nosotros, también hay ngen localizados en lugares donde se realizan las ceremonias culturales, hay que saber entrar a esos lugares no se puede llegar y entrar sin pedir permiso y eso es lo que les ha costao a los winkas".

"El newen es una fuerza positiva que nosotros tenemos los Mapuches, la energía, porque todo ser humano tiene el ngen, el espíritu le dicen los huincas... consagrándome, en tal parte tengo que recibir la fuerza del ngen...nosotros como Mapuche tenemos nuestro equilibrio con nuestro entorno, según nuestra cosmovisión, nuestra espiritualidad...necesitamos de todo el entorno para estar en equilibrio y en armonía, todo para nosotros tiene su espiritualidad, su protección"

\section{Conclusiones}

La realización de la trashumancia por parte de la comunidad Pedro Currilem, puede ser entendida como una forma de habitar, significar y construir este territorio de montaña. La serie de prácticas y actividades identificadas se realizan de manera coordinada y están basadas en los conocimientos locales del espacio geográfico de los miembros de la comunidad. Estas prácticas generan una representación propia y particular de la actividad en este sector y ejemplifican cómo el quehacer de las colectividades humanas, se plasma en su territorio, transformando este espacio geográfico en un espacio vivido, único, con sentidos y valoraciones específicas, no extrapolables a otros casos, lo que contribuye a fortalecer la identidad local y comunitaria.

Es interesante recordar cómo la noción de etno-territorio, planteada por Molina (1995), puede ser aplicada al caso de Pehuenco, dado que ésta implica una delimitación que surge de la construcción colectiva del espacio en la cual se plasman saberes geográficos. Durante el ejercicio de dotar de significado a la cartografía muda del territorio, a través del mapeo colectivo, fue posible delimitar y representar el espacio de montaña, identificando lugares significativos y espacializando prácticas a partir del conocimiento local o in situ. Materializar este conocimiento espacial y otorgarle significados a través de las acciones, la toponimia y las historias locales, a los lugares habitados, permite reafirmar que el conocimiento ecológico local es un saber acumulativo y dinámico, el cual puede trascender lo meramente descriptivo y transformarse en un recurso valioso, para por ejemplo, la gestión local del territorio o para la búsqueda de manejos más eficientes de los recursos naturales (Reyes 2007; Berkes et al. 2000). Lo anterior puede ser especialmente relevante para el caso de prácticas propias de la trashumancia como el piñoneo. En este sentido, cabe mencionar que en el año 2018, Araucaría araucana fue declarada en Chile como especie en peligro de extinción, específicamente para el caso de la Cordillera de Nahuelbuta; sin embargo, aún no existen antecedentes suficientes que permitan dimensionar el impacto que esta nueva categoría de protección podría tener sobre las comunidades que realizan la recolección del piñon, no solo desde una perspectiva económica sino que también cultural y simbólica.

Es importante señalar que en Chile, el mayor desafío que las prácticas trashumantes enfrentan, es su mantenimiento y continuidad en el tiempo. En este sentido, Pehuenco y la comuna de Lonquimay no están ajenas a las problemáticas de los espacios rurales, donde el aislamiento funcional favorece la migración, especialmente de los más jóvenes a las ciudades. Lo anterior, implica una disminución de las personas que ejercen actividades agrícolas y pastoriles como las aquí descritas, siendo actualmente esta actividad realizada mayoritariamente por adultos y adultos 
mayores, evidenciándose un alto riesgo de pérdida de conocimientos espaciales y locales como los que se han descrito. Finalmente, este trabajo buscó, a partir de un caso de estudio específico, contribuir a la discusión geográfica de las formas en que se construye y significa un espacio de montaña del sur de chile, a partir de la visión de las territorialidades pehuenches, las cuales nos permiten evidenciar otras perspectivas del uso y apropiación del espacio.

\section{Bibliografía}

AHUMADA, M.; PALMA, R.; CENTRON, A.; RAMÍREZ, S.; HAUENSTEIN, E.; GONZÁLEZ, M. y PÉREZ, G. Pauta de condición de las veranadas en la IX Región de La Araucanía. Temuco: Ministerio de Agricultura, Servicio Agrícola y Ganadero (SAG), Depto. de Protección de los Recursos Naturales Renovables, 1999.

ALISTE, E.; NÚÑEZ, A. Las fronteras del discurso geográfico: El tiempo y el espacio en la investigación social. Chungará, Revista de Antropología Chilena, 2015, Vol. 47, № 2, p. 287-301.

ANDALUZ, C.; MÉREGA, J.L \& PALMILI, G. Review of the Literature on Pastoral Economics and Marketing: South America. Report Prepared for the World Initiative for Sustainable Pastoralism. Argentina: IUCN EARO, 2006.

ARANDA, X. Un tipo de ganadería tradicional en el Norte Chico, la trashumancia. Centro demostrativo "corral de julio". Santiago: Universidad de Chile, Departamento de Geografía, 1971.

BAILLY, A. Las fronteras: representaciones, poderes y divisiones territoriales. En A. NÚÑEZ, R. SÁNCHEZ y F. ARENAS (editores), Fronteras en movimiento e imaginarios geográficos. La cordillera de Los Andes como espacialidad socio-cultural. Santiago de Chile: Geolibros-RIL Editores, 2013.

BELLO, A. Nampülkafe. El Viaje de los Mapuches de La Araucanía a las Pampas Argentinas. Territorio, Política y Cultura en los Siglos XIX y XX. Temuco: Universidad Católica de Temuco, 2011.

BENGOA, J. Historia del Pueblo Mapuche: siglo XIX y XX. Santiago: Editorial Sur, 2000.

BERKES, F.; COLDING, J. \& FOLKE, C. Rediscovery of traditional ecological knowledge as adaptive management. Ecological Applications, 2000, N¹0, p. 1251-1262.

BRAGG, S., HAUENSTEIN, E y LATSAGUE, M. 1986. Transecto etnobotánico del sector mapuche. Cultura, Hombre, Sociedad, 1986, N³(6), p.57-80.

COMISIÓN VERDAD HISTÓRICA Y NUEVO TRATO CON LOS PUEBLOS INDÍGENAS. 2003. Informe de la Comisión Verdad Histórica y Nuevo Trato con los Pueblos Indígenas. Disponible en internet: https://bibliotecadigital.indh.cl/handle/123456789/268

CORREA, M., MOLINA, R. y YÁNEZ, N. La Reforma Agraria y las tierras Mapuches. Santiago: LOM Ediciones, 2005. 
FOERSTER, R. Sociedad mapuche y sociedad chilena: la deuda histórica. Polis [En línea], 2002. Disponible en internet: http://journals.openedition.org/polis/7829

GARCÍA, P. La Mesta. Madrid: Historia 16, 1990.

GIMÉNEZ, G. La cultura como identidad y la identidad como cultura. México: Consejo Nacional de la Cultura y las Artes, 2005.

GOBIERNO DE CHILE. Boletín de información legislativa No 25/2016 364ª Legislatura de Sesiones del Congreso Nacional. 2016. Disponible en internet:

http://www.minsegpres.gob.cl/wp-content/uploads/2016/08/25-LEG-364a-29-08-2016-BOLETIN-N-25-2016.pdf

GONZÁLEZ, J. y BERNEDO, P. Cartografía de la transformación de un territorio: La Araucanía 18521887. Revista de Geografía Norte Grande, 2013, N54, p.179-198.

GONZÁLEZ, J.; OTEROS, E.; MARTÍN, B.; LÓPEZ, C.; ZORRILLA, P. y MONTES, C. La trashumancia en la Cañada Real Conquense: Valores ecológicos, sociales y económicos asociados a una práctica ganadera tradicional. Informe de síntesis para responsables de políticas. Madrid: Universidad Autónoma de Madrid, 2012.

GREBE, M. El subsistema de los ngen en la religiosidad mapuche. Revista Chilena de Antropología, 1993-1994, N²12, p. 45-64.

GUERRA, J.P. Pastoreo Trashumante en el Valle del Aconcagua. Tesis para optar al grado de antropólogo. Santiago: Universidad Academia de Humanismo Cristiano, 2005.

HAUENSTEIN, E. Composición florística de Praderas Altoandinas de la zona de Lonquimay (IX región, Chile). Agro Sur, 2002, №31, p. 8-20.

HUILIÑIR, V. El rol de las veranadas en territorio pehuenche de Alto Bio Bio. Despertando latitudes, 2010, No2, p. 17-24.

HUILIÑIR, V. Los senderos pehuenches en Alto Biobío (Chile): articulación espacial, movilidad y territorialidad. Revista de Geografía Norte Grande, 2015, N62, p. 47-66.

LEFEBVRE, H. La producción del espacio. París: Anthropos, 1974.

LINDÓN, A. y HIERNAUX, D. (Editores) Los giros de la Geografía Humana. Desafíos y horizontes. México: UAM, Anthropos, 2010.

MCGAHEY, D., DAVIES, J., HAGELBERG, N., \& OUEDRAOGO, R. Pastoralism and the Green Economy - a natural nexus? Nairobi: IUCN and UNEP. X, 2014. 
MARTÍNEZ, N. Prácticas cotidianas de ancestralización de un territorio indígena: el caso de la comunidad pehuenche de Quinquén. Revista de Geografía Norte Grande, 2015, № 62, p. 85-107.

MOLINA, R. Reconstrucción de los etno-territorios. En: Tierra, territorio y desarrollo indígena. Temuco: Instituto de Estudios Indígenas, 1995, p. 111-118.

MOLINA, R. y CORREA, M. Territorio y comunidades pehuenche del Alto Bío Bío. Santiago: CONADI-AGCI, 1996.

MOLINA, R. y CORREA, M. Territorio y comunidades pehuenche de Lonquimay. Estudio área de desarrollo indígena de Lonquimay. Temuco: Instituto de Estudios Indígenas, Universidad de la Frontera-CIID-GTZ, 1997.

MOLINA, R. Los collas de la cordillera de Atacama. En: BENGOA, J. La memoria olvidada: historia de los pueblos indígenas de Chile. Santiago: Cuadernos Bicentenario, Presidencia de la República, 2004.

MOLINA, R. Collas y Atacameños en el desierto y la Puna de Atacama y Valle de Fiambalá: sus relaciones transfronterizas. Tesis doctoral en Antropología. Arica-Antofagasta: Universidad de Tarapacá-Universidad Católica del Norte, 2010.

MOLINA, R. Los otros arrieros de los valles, la puna y el desierto de Atacama. Chungará, Revista de Antropología Chilena, 2011, N43(2), p. 177-187. Disponible en internet: https://dx.doi.org/10.4067/ s0717-73562011000200002

MONTAÑEZ, G y DELGADO, O. Espacio, territorio y región: conceptos básicos para un proyecto nacional. Cuadernos de Geografía, 1998, VII, p. 120-134.

NÚÑEZ, A., ARENAS, F. y SÁNCHEZ, R. De la montaña geográfica a las geografías de montaña. Un análisis de Los Andes chileno desde la geografía social. Journal of Alpine Research, Revue de géographie alpine [En ligne], 2017, Nº105-4 Disponible en internet: http://journals.openedition. org/rga/3791.

NÚÑEZ, A., R. SÁNCHEZ y F. ARENAS (Editores). Fronteras en movimiento e imaginarios geográficos. La Cordillera de Los Andes como espacialidad sociocultural. Santiago: RIL Editores y Ediciones de la Pontificia Universidad Católica de Chile, Serie Geolibros, 2013.

NÚÑEZ, L. y NIELSEN, A. (Editores) En ruta: Arqueología, historia y etnografía del tráfico sur andino. Córdoba: Encuentro Grupo Editor, 2011.

PÉREZ, P. y MATEO, T. La importancia ecológica de la trashumancia. Revista Investigación y Ciencia. $2011, \mathrm{~N}^{\circ} 414$, p. s/n.

RAZETO, J. y SUCKEL, H. Trayectoria Agraria de la Comarca de Aconcagua. En CANALES, A., CANALES, M., RAZETO, J. (Editores) Aconcagua La Comarca. Aconcagua: Ediciones Almendral, 2007. 
REYES, V. Conocimiento ecológico tradicional para la conservación: dinámicas y conflictos. Papeles, 2009, N¹07, p. 39-55.

RISLER, J. y ARES, P. Mapeo Colectivo: Profundizando la mirada sobre el territorio. Buenos Aires: Tinta Limón, 2013.

SCHIAPPACASSE, V. y NIEMEYER, H. Apuntes para el estudio de la trashumancia en el Valle de Camarones (Provincia de Tarapacá, Chile). Estudios Atacameños, 1975, III, p. 49-52.

SEPÚLVEDA, B. El territorio mapuche en Chile: perspectivas geográficas. Revista Geográfica del Sur, 2012, N³, p. 9-13.

TACÓN, A., FERNÁNDEZ, U. y ORTEGA, F. El Mercado de los PFNM y su papel en la conservación de la Ecorregión de los Bosques Valdivianos. Red de productos PFNM de Chile. Valdivia: WWF-CODEFF, 2000.

THER, F. Antropología del Territorio. Polis, 2012, N³2, p. 493-510.

TOMASI, J. Espacialidades pastoriles en las tierras altoandinas: Asentamientos y movilidades en Susques, puna de Atacama (Jujuy, Argentina). Revista de Geografía Norte Grande, 2013, No 55, p. 67-87.

TORREJÓN, F. Variables Geo históricas en la Evolución del Sistema Económico Pehuenche Durante el Periodo Colonial. Universum, 2001, XVI, p. 219-236.

TORRES, F. Henri Lefebvre y el espacio social: aportes para analizar procesos de institucionalización de movimientos sociales en América Latina - La organización Barrial Tupac Amaru (Jujuy-Argentina). Sociologías, 2016, Vol.18, №43, p. 240-270.

UGARTE, R. Los pehuenches y el espacio reduccional. Revista de Geografía Norte Grande, 1997, $N^{\circ} 24$, p. $175-181$.

VILLALOBOS, S. Los pehuenches en la vida fronteriza. Santiago: Ediciones Universidad Católica de Chile, 1989.

ZUSMAN, P., LOIS, C. y CASTRO, H. Prefacio. En: ZUSMAN, P., LOIS, C. y CASTRO, H. Viajes y Geografías. Exploraciones, turismo y migraciones en la construcción de lugares. Buenos Aires: Prometeo Libros, 2007. 